\title{
David Oliver: The TaxPayers' Alliance, Hancock, and health technology
}

\author{
David Oliver consultant in geriatrics and acute general medicine
}

Berkshire

On 24 April the TaxPayers' Alliance published a report on the potential benefits of automation for the NHS, social care, and wider local government services. ${ }^{1}$ The previous day the organisation, which describes itself as a think tank and "non-partisan grassroots campaign for lower taxes," which "speaks up for taxpayers," announced that it was launching the report "with" Matt Hancock, secretary of state for health and social care in England. ${ }^{3}$ I can't see any evidence in the report of his involvement, beyond an enthusiastic foreword.

The report states, "There are barriers to entry into the NHS for companies offering innovative healthcare solutions. Many are being addressed and in the long term it's crucial that the NHS remains open to new ideas and innovation." These "barriers," of course, prevent entry to a tax funded public service used by taxpayers.

But the NHS doesn't exist to provide commercial opportunities for the technology sector. The NHS should define the challenges it might use technology to meet, rather than having technology forced on it by ministers-and it should insist on rigorous evaluation and evidence, not infomercials penned by the technology providers.

Hancock has made adopting technology in the NHS a key mission of his time as health secretary. He's called for a "tech revolution" in the NHS and social care, insisting on a common set of mandatory open standards for IT providers around interoperability and compatibility with other software and devices. ${ }^{45}$ Those who can't meet these standards will be "phased out." ${ }^{\prime 6} \mathrm{He}$ insisted on opening the NHS market to providers of existing "off the shelf" technologies rather than having the NHS develop its own bespoke solutions.

What he did not insist on-nor does the government's wider strategy for digital technology — was rigorous, independent evaluation of new technologies or any independent appraisal and review. It's not clear how the government's proposed regulatory evaluation "sandbox" will work or whether private sector providers will continue to hide from freedom of information requests because of commercial sensitivity. It seems that health technology will be held to different standards of evidence than other service innovations or treatments, with a focus on rapid adoption and ensuring faster access to the market than health and social care offers.

The TaxPayers' Alliance report is titled Automate the State-and labelled on the alliance's website as "research." It says that the "potential value of time released for NHS staff through improved productivity from increased automation is estimated to be $£ 12.5$ billion a year." It provides a few examples of innovation in practice, but it isn't "research" as I understand it. It's full of assertions and assumptions. The documents it references are selective and largely free of empirical data. No methods, workings, or peer review are in evidence, making it hard to scrutinise the claims or to look for biases. Contrast this with the NHS England funded systematic literature review on Technology Enabled Care Services, which showed very patchy and inconclusive data across a range of health technology.

Meanwhile, the TaxPayers' Alliance itself gives me cause for concern. Its name suggests a mandate to represent taxpayers, but its agenda is one of a small state and greater marketisation of public services. Yet many taxpayers support strong public services, including a free-at-point NHS, and want less marketisation. The alliance has also been criticised for a lack of transparency about its funding sources, their provenance, and its own methods. ${ }^{8-10}$

I'm a taxpayer. I work for the NHS. And I think that Hancock should be far more careful about which organisations he endorses or promotes if he doesn't want to alienate staff and service users alike.

\section{Competing interests: See www.bmj.com/about-bmj/freelance-contributors.}

Provenance and peer review: Commissioned; not externally peer reviewed.

Ramanauskas B. Automate the state: embracing technology in health and social care. TaxPayers' Alliance. Apr 2019. https://d3n8a8pro7vhmx.cloudfront.net/taxpayersalliance/ pages/16535/attachments/original/1556005812/Embracing_technology_in_health_and_ social_care.pdf?1556005812.

2 TaxPayers' Alliance. https://www.taxpayersalliance.com/.

3 TaxPayers' Alliance. Automate the state: health and social care. 23 Apr 2019. https:// www.taxpayersalliance.com/automate_the_state_health_and_social_care. 
4 Crouch H. Hancock's "tech revolution" to include mandatory open standards. Digital Health 2018 Oct 17. https://www.digitalhealth.net/2018/10/hancock-tech-revolution-mandatoryopen-standards/.

5 Department of Health and Social Care. Policy paper: the future of healthcare-our vision for digital, data and technology in health and care. 17 Oct 2018. https://www.gov.uk government/publications/the-future-of-healthcare-our-vision-for-digital-data-and-technologyin-health-and-care/the-future-of-healthcare-our-vision-for-digital-data-and-technology-inhealth-and-care.

6 Crouch H. Hancock issues stern warning to health IT suppliers. Digital Health 2018 Sep 7. https://www.digitalhealth.net/2018/09/hancock-health-it-suppliers/.

7 NHS England. Technology enabled care services: resource for commissioners. Jan 2015. https://www.england.nhs.uk/wp-content/uploads/2014/12/TECS_FinalDraft_0901.pdf.
8 Booth R. Who is behind the Taxpayers' Alliance? Guardian 2009 Oct 9. https://www. theguardian.com/politics/2009/oct/09/taxpayers-alliance-conservative-pressure-group. 9 Cadwalladr C. TaxPayers' Alliance concedes it launched smears against Brexit whistleblower. Guardian 2018 Nov 11. https://www.theguardian.com/politics/2018/nov/ 11/brexit-whistleblower-shahmir-sanni-taxpayers-alliance-concedes-it-launched-smears. 10 Evans R, Pegg D, Lawrence F. Taxpayers' Alliance received over £223k in foreign donations. Guardian 2018 Nov 20. https://www.theguardian.com/politics/2018/nov/20/ taxpayers-alliance-received-hundreds-of-thousands-in-foreign-donations.

Published by the BMJ Publishing Group Limited. For permission to use (where not already granted under a licence) please go to http://group.bmj.com/group/rights-licensing/ permissions 